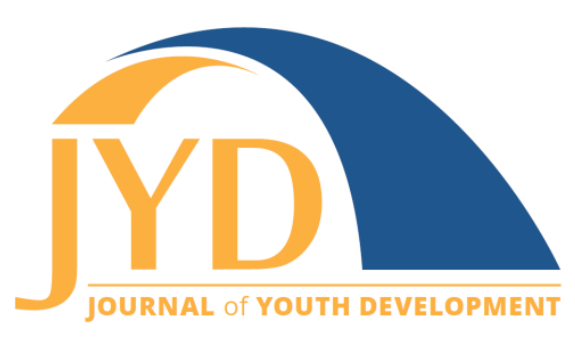

http://jyd.pitt.edu/ | Vol. 15 Issue 3 DOI 10.5195/jyd.2020.948 | ISSN 2325-4017 (online)

\title{
Shaping Positive Summertime Experiences for All Youth to Promote Healthy Development
}

\author{
Rebekah Hutton \\ National Academies of Sciences, Engineering, and Medicine \\ rhutton@nas.edu
}

\section{Priyanka Nalamada}

National Academies of Sciences, Engineering, and Medicine

pnalamada@nas.edu

\begin{abstract}
Shaping Summertime Experiences: Opportunities to Promote Healthy Development and Well-Being for Children and Youth was released by the National Academies of Sciences, Engineering, and Medicine in September 2019. This multidisciplinary committee authored report examines evidence on outcomes of summertime experiences for children and youth in 4 areas of well-being: (a) academic learning and enrichment, (b) social and emotional development, (c) physical and mental health, and (d) safety, risktaking, and pro- and anti-social behaviors. Using a systems perspective, the committee looked at how social, physical, and economic environments interact to promote or limit access for children and youth to opportunities for positive development, healthy behaviors, safety, and well-being during the summer. The committee's recommendations are intended to improve planning, administration, and coordination of summertime programs and services, improving availability, access, and equity of summertime programs; and advancing data collection efforts.
\end{abstract}

Key words: summer, summertime, summer programs, development

\section{Introduction}

The summer months present a major departure from the structure, resources, and support systems that are available to the vast majority of children, youth, and their parents during the traditional school year. For those with few economic resources and limited income, the opportunity to access continued school-year supports and resources in the following domains-

(cc) EY New articles in this journal are licensed under a Creative Commons Attribution 4.0 License. This journal is published by the University Library System, University of Pittsburgh and is cosponsored by the University of Pittsburgh Press. The Journal of Youth Development is the official peer-reviewed publication of the National Association of Extension 4-H Agents and the National AfterSchool Association. 
academic learning, social and emotional development, physical and mental health, and prosocial behavior-is often constrained. This contributes to differential summertime experiences for children and youth based on their socioeconomic status and racial/ethnic background, which can result in losses in some domains, gains in some domains, and lack of progress in others. Understanding the accessibility of existing programs and services, the characteristics of effective programs and practices, and the diversity of families needing to be served is critical to improving the summertime experiences of America's children and youth.

The Committee on Summertime Experiences and Child and Adolescent Education Health and Safety authored a report published by the National Academies of Sciences, Engineering, and Medicine to examine the state of the science on how summertime experiences affect school-age children (K-12) across four areas of well-being: (a) academic learning and opportunities for enrichment; (b) social and emotional development; (c) physical and mental health and healthpromoting behaviors; and (d) safety, risk-taking, and anti-and pro-social behavior. The Committee's report, Shaping Summertime Experiences: Opportunities to Promote the Healthy Development and Well-Being of Children and Youth, offers recommendations that identify practices with the potential to promote positive developmental trajectories for all children across multiple dimensions of well-being. ${ }^{1}$

In addition to standard analytical approaches (e.g., social psychology, child development, econometrics, etc.), a systems approach to thinking about the summer landscape played an important role in helping the committee to address its task. Social, economic, and environmental factors influence behaviors, choices, access, and equity. By looking at the sectors and agents with roles and functions in summertime experiences, the committee was able to understand the consequences when sectors (e.g., education sector, health sector) and agents (e.g., schools, camps, non-profits) operate independently in trying to contribute to this space and gaps where there are opportunities for improvement. It also underscored the importance of self-directed activities for children, youth, and families.

\footnotetext{
${ }^{1}$ This article contains previously published material from the National Academies of Sciences, Engineering, and Medicine Consensus Study report released in 2019 by the National Academies Press, Washington, D.C. Suggested citation for the full report: National Academies of Sciences, Engineering, and Medicine. (2019). Shaping Summertime Experiences: Opportunities to Promote Healthy Development and Well-Being for Children and Youth. Washington, DC: The National Academies Press. https://doi.org/10.17226/25546. This report was authored by the Committee on Summertime Experiences and Child and Adolescent Education, Health, and Safety. Appreciation goes to the full committee for their work on this study and to Martín-José Sepúlveda and Karl Alexander for their reviews of earlier drafts of this article. This study was funded by the Robert Wood Johnson Foundation and the Wallace Foundation.
} 


\section{Summertime: Risks and Opportunities}

Summer provides a unique window of opportunity during the year to engage families and leverage the strengths and resources of families, communities, and other stakeholders to improve the education, health, safety, and well-being of children and youth. The diverse socioenvironmental settings in which children and youth live, play, and work determine the availability of and accessibility to programs and services during the summer months. These experiences can affect academic achievement, health, social and emotional development, and safety of children and youth, with those in disadvantaged communities at risk for worse outcomes. When schools close for the summer, children, youth, and families may lose a number of vital supports, such as access to healthy meals, access to medical care, daily supervision, and structured enrichment opportunities. These losses make summer a time of increased vulnerability for many children and youth-especially those from communities and families with fewer resources. While children from higher- and middle-income families may not be affected by these losses, many families with fewer resources cannot fill this gap.

There are opportunities for systems and agents to implement innovative new programs and extend effective practices that already exist during the school year into the summer period. Summertime presents an opportunity to leverage the strengths of families, communities, and stakeholders to improve existing conditions and develop new approaches to advance the trajectories of children and youth in the four areas of well-being that the committee examined. The assets and priorities of communities must be central to the planning, development, design, and evaluation of summertime programs and services.

\section{Socioeconomic Status and Access to Summertime Experiences}

Summertime experiences across youth populations vary by social and economic circumstances, with consequences for children's healthy development that can be long-lasting. American youth have a substantial amount of discretionary time when not in school (Mahoney et al., 2005), yet the summertime experience of many children is not characterized by a healthy balance of structured vs. unstructured and self-directed activities in organized programs with a range of other family, peer, and self-directed experiences.

Family poverty can harm children's healthy development insofar as it affects access to resources, and "families who occupy different SES niches because of parental education, income, and occupation have strikingly different capacities to purchase safe housing, nutritious meals, high-quality child care, and other opportunities that can foster health, learning, and 
adaptation" (National Research Council and Institute of Medicine, 2000, p. 268). Across the board, families are spending more money on children than they formerly did, measured as a percentage of total income, but high-income families spend more than twice as much, on average, as low-income families. Such differences contribute to significant inequalities in access to summertime opportunities across the income spectrum (McLanahan \& Jacobson, 2015).

The average cost of summer programs can be viewed in the context of varying household incomes. For example, the average reported cost of a summer program nationally in 2014 was $\$ 288 /$ week (Afterschool Alliance, 2015). According to the 2018 federal poverty guidelines, a family of four living at 100 percent of the poverty level has $\$ 25,100$ in yearly income or approximately $\$ 483 /$ week. As this comparison of the cost of one week of summer programs and the weekly income of a family living at poverty level shows, for many families it is virtually impossible to involve their children in a summer program with average costs. Because so many children in the United States are growing up in poverty, this cost presents a significant barrier to access. By contrast, families with higher incomes spend significantly more on goods and services aimed at enriching the experiences of their children. In 2005-2006, those in the highest income quintile on average spent $\$ 7,000$ more than those in the bottom quintile, with the differences most pronounced for activities such as music lessons, travel, and summer camps (Duncan \& Murnane, 2011). Such differences contribute to significant inequalities in access to summertime opportunities across the income spectrum (McLanahan \& Jacobsen, 2015).

\section{Summertime Experiences and Effects on Development}

All children have basic developmental needs, including the need for adequate nutrition and the need for safety that must be met as a critical precondition for summer programs and services. Children and youth who live in less advantageous circumstances (e.g., with poverty or food insecurity or in neighborhoods with high incidence of violence, crime, or over-policing) face numerous obstacles in having their needs met across the four developmental domains and in accessing positive summer experiences. Children need adequate nutrition and safety for health and social/emotional stimulation to support psychological and cognitive development (Hoynes et al., 2016; Malin et al., 2018). Basic needs for food and safety are year-round needs and, of course, do not pause during the summer.

Research also shows that features of the social context are critical to the development of physical, intellectual, psychological, social, and emotional skills and competencies (i.e., internal 
assets). In 2002, a National Research Council committee identified eight features of settings that support positive development for youth:

- Physical and psychological safety

- Appropriate structure

- Supportive relationships

- Opportunities to belong

- Positive social norms

- Support for efficacy and mattering

- Opportunities for skill building

- Integration of family, school, and community efforts

However, optimal implementation of these features will vary across different types of settings (e.g., home vs. summer camps) and for youth of different ages (e.g., elementary vs. high school-aged students) and backgrounds. For example, appropriate structure for elementary school students will include greater adult oversight and supervision than for high school age youth.

The committee found little systematic research concerning the impact of summer on the developmental trajectories of school-age children and youth across all four areas of well-being. In most cases, the committee found far more information on how summer influences academic learning and obesity relative to other developmental outcomes of interest. It is also important to note that a number of the gaps in developmental outcomes between children and youth from higher and lower socioeconomic backgrounds and from different racial and ethnic groups are present before school entry, including gaps in the academic, social-emotional, and health domains.

It is important to consider how the social conditions related to socioeconomic status may impact social and emotional skill development. Disparities have been documented in the social and emotional skills that children have when they first enter formal schooling-disparities that track with socioeconomic status and related social conditions (Greenberg \& Weissberg, 2018; Halle et al., 2009; Reardon \& Portilla, 2016). Thus, it must be acknowledged that it may be challenging for a single, stand-alone summer program to redress such gaps and that the effects of social conditions may be exacerbated in the summer months for youth from communities with higher levels of stressors and fewer opportunities for enriching programs or activities. 


\section{Program Participation and Outcomes}

The committee classified quantitative outcomes evidence into three categories-conclusive, moderate, and suggestive-based on certainty that programs created the measured effects and would do so in other contexts:

- Conclusive evidence. There is strong certainty that the program created positive outcomes for many children and youth that could be replicated in other settings. This evidence comes from a well-conducted, rigorous, experimental design for causal inference- a randomized controlled trial (RCT) including many children or youth across more than one site. In an RCT, participants are randomly assigned to either receive the intervention or participate in a comparison group that does not receive the intervention, providing a robust counterfactual.

- Moderate evidence. There is reasonable certainty that the program created positive outcomes for children and youth. Evidence in this category comes mainly from studies with well-conducted quasi-experimental designs. These designs approximate experimental research by identifying a comparison group that is similar to the program participants' observed pre-intervention characteristics (e.g., test scores, grade, race, gender). Alternatively, the evidence may come from RCTs where the generalizability of the findings is uncertain due to having a small number of children and youth in the study or due to being conducted at only one site.

- Suggestive evidence. There is evidence of a relationship between program participation and youth outcomes; however, certainty regarding causality is low and generalizability may be low as well. Evidence in this category comes from three types of studies (a) RCTs with design problems; (b) studies that include a comparison group that was not rigorously matched to intervention participants but includes statistical controls to help account for in lack of rigor in matching; and (c) pre/post design studies that measure changes in participant outcomes over time, but do not have a comparison group of children or youth who did not participate in the program.

There is evidence of effectiveness for many different types of programs, but the outcomes research base is not representative of all the types of summer programming available and it does not represent the full range of populations served or all types of agents offering programs. For instance, the majority of identified outcomes studies examined academic summer programs targeted to youth who are low-income, disadvantaged, or performing below grade level. Even within the academic programs, the committee found far more evaluations of reading than of mathematics, writing, or science. Other types of popular programs, including sports camps and 
religious camps, have not been rigorously studied. Also, the literature does not investigate the benefits of the most common pattern of participation in summer programs, namely, participation in multiple, short programs over multiple summers.

Few summer programs have been studied by trials replicating them in different contexts. Many of the identified studies are one-off program evaluations, and many contain little information regarding implementation, making exact replication difficult. Further, many of the randomized controlled studies include small numbers of children and youth because the programs themselves are intentionally small. Studies of programs that have involved large populations have not been randomized controlled trials. As a result, the committee found few studies demonstrating conclusive evidence of benefits, but rather more moderate or suggestive evidence.

\section{Key Findings From the Program Effectiveness Literature}

The existing literature related to program effectiveness does provide some key findings related to the four outcome domains examined by the committee:

- The rigorous outcomes research base is not representative of all the types of summer programming and does not represent all types of populations served by summer programs or all agents offering summer programs.

- The rigorous outcomes literature does not investigate the benefits of participating in multiple programs over one or multiple summers.

- Few summer programs have had replicated trials in different contexts or track outcomes in the longer term.

- Due to study design, few studies demonstrate conclusive evidence of benefits; instead, the evidence is more moderate and suggestive.

- There is no evidence of significant negative outcomes from the reviewed studies; this may stem from the low probability of harm from summer programming or from a bias in publication toward positive findings.

- The majority of studies found evidence of effectiveness; however, studies did not typically find that programs were effective in producing all measured outcomes.

- Regular participation, sufficient duration, and targeted programming to meet youth needs appear to be correlated with program effectiveness.

\section{Safety, Risk-Taking, and Pro- and Anti-social Behaviors}

- No rigorous outcome studies examined whether summer programs improve physical safety or supervision. 
Shaping Positive Summertime Experiences for Youth

- There is moderate evidence indicating that summer programs designed to reduce risky behaviors such as alcohol use and unsafe sex are effective.

- There is strong evidence that youth employment programs for adolescents at risk of crime involvement can decrease violent-crime arrests.

Physical and Mental Health

- There is suggestive evidence that summer programs designed to promote weight loss can be effective in reducing weight, BMI, and promoting fitness.

- Programs providing targeted interventions to children and youth with mental health needs, such as depression or anxiety, can be effective in promoting mental health outcomes.

\section{Social and Emotional Development}

- There is moderate evidence that specialized programs designed to meet the specific needs of specific groups of children and youth can improve social and emotional skills and abilities.

- Suggestive evidence exists for the social and emotional benefits of medical camps and recreational camps.

\section{Academic Learning and Enrichment}

- Academic learning was the most frequently studied group of outcomes in the literature and the most frequently studied type of program.

- Academic learning programs have been tested in multiple contexts with large numbers of children and youth.

- There is evidence of effectiveness for many types of summer academic learning programs, including voluntary single and multi-subject programs (strong, moderate, and suggestive), mandatory programs (moderate), and at-home programs (strong and suggestive).

The research base demonstrates that summer programming can measurably benefit youth across multiple domains. Because the overall evidence base is fragmented and not representative of all programs available to children and youth over the summer, it is particularly important to understand what factors increase the quality and effectiveness of summer programs. The following key themes emerged in the literature reviewed and the testimony heard by the committee. 


\section{Intentional Design to Meet Student Needs and Desired Outcomes}

As discussed earlier, programs designed to meet specific students' needs and that link their content to desired student outcomes appear to be particularly successful. For instance, programs designed to address the social and emotional needs of children and youth with disabilities demonstrated moderate or suggestive evidence of effectiveness. This suggests that the efficacy of these programs might be tied to the intentional targeting of the program to a population that has been identified in need of such a program (McCombs et al., 2019). Similarly, meta-analyses of out-of-school-time programs have found that programs designed to enhance students' social and emotional skills were successful in doing so, while programs that were not intentionally addressing these skills tended to be ineffective in improving these skills (Durlak et al., 2011).

Based on testimony provided to the committee, cultural responsiveness is identified as a key component of intentional programming. Programs that are not responsive to students' cultural values, beliefs, and backgrounds are, at a minimum, unlikely to attract and retain youth, and at worst could do harm by inflicting offensive beliefs or actions on students.

In the context of summer, and concerning out-of-school-time programs broadly, cultural responsiveness requires considering both the staff practices that directly influence youth experiences (e.g., behavior management strategies, expectations for youth, and interaction styles) and the organizational structures (e.g., program communications, written rules and policies) that both directly and indirectly influence youth access to and experiences in programs (Simpkins et al., 2017). For example, program structures should connect to content that is relevant to youths' lives in culturally meaningful ways, and in their interactions with youth, staff should support opportunities to explore youths' cultural identity. These approaches are relevant for summer experiences as well.

\section{Sustained Attendance}

Research also clearly demonstrates that students need to attend summer learning programs to benefit from them (Augustine et al., 2016; Borman et al., 2005; Borman and Dowling, 2006; Kilanowski and Gordon, 2015; McCombs et al., 2009). For instance, in a study of an academic voluntary summer learning programs, the authors found that students who attended the summer 2013 program for at least 20 days benefited in mathematics in the fall of 2013 relative to comparison-group students, and those effects persisted through spring 2014. After the summer 2014 program, high attenders outperformed the comparison group in both 
mathematics and language arts in the fall and spring. These benefits were also demonstrated on state academic assessments in spring (Augustine et al., 2016).

\section{Sufficient Duration}

Summer programs should be of sufficient duration to meet the goals established for the program. Duration seems particularly important for academic programs. None of the programs reviewed that lasted 3 weeks or less resulted in benefits for children and youth. For voluntary academic programs, recent research suggests programs should last at least 5 weeks so they can provide sufficient content to demonstrably improve student achievement (Augustine et al., 2016). There are also indications that greater benefits accrue across multiple summers of participation (Augustine et al., 2016); for example, a study of Horizons National, a multisummer program, found academic benefits that accrued after multiple summers of participation (Concentric Research and Evaluation, 2018).

\section{Key Conclusions and Implications for Policy and Practice}

Summer programs can be designed to promote children's and youths' safety, physical and mental health, social and emotional development, and academic learning, but they must be targeted to the needs of participants, have programming linked to desired outcomes, be of sufficient duration, and promote strong attendance. The research evidence on summer program effectiveness does not represent the totality of experiences and programs available to children and youth over the summer, and therefore, cannot be the sole basis upon which to make decisions regarding appropriate programming. Research is needed on the impact of summer programs on the developmental trajectories of children and youth over the course of multiple years. The current literature examines one-off programs but does not address the effect of the multiple experiences children and youth have over the course of their childhood. Research is needed on different types of programs, replication studies in different contexts, and programs serving underserved populations.

\section{Research Needs for Evidence-Based Summertime Programs and Practices}

More research is needed to better understand how developmental trajectories are affected during the summer months and the role that key social contexts and the agents within them can play in shaping positive experiences and outcomes. In its examination of the evidence, the committee identified existing gaps and specific needs for future research with the potential to 
Shaping Positive Summertime Experiences for Youth

inform evidence-based summer programs and practices and to increase understanding of the summertime experiences of children and youth in the United States. A key gap that the committee identified was in the area of data collection. In its review of the evidence related to the four outcome domains, the committee found multiple instances where data collection that occurred during the school year ceased during the summer months, leaving gaps in the available evidence related to summertime experiences and the effect of summer on developmental growth.

The committee also identified numerous examples of existing data sets where it was not possible to disaggregate data by month or season. Having monthly and/or seasonal data available would make it possible to attain valuable insights into the experiences of children and youth during the summer. Improving and better integrating data sources and systems would help to inform policy, practice, and research.

A selection of the research needs related to improving the program effectiveness of evidencebased programs, improving understanding of developmental trajectories, and improving summertime experiences for underserved populations is presented in Table 1. 


\section{Table 1. Selected Research Needs to Inform Evidence-Based Summertime Programs} and Practices

\begin{tabular}{|c|c|}
\hline Category & Specific research needs \\
\hline $\begin{array}{l}\text { Effectiveness of } \\
\text { programs and } \\
\text { practices }\end{array}$ & $\begin{array}{l}\text { - Examine how participation in summer programs over multiple years affects } \\
\text { outcomes for children and youth. } \\
\text { - Conduct replication studies to understand how different contexts may change } \\
\text { outcomes. } \\
\text { - Review existing public/private employer summertime programs for effectiveness } \\
\text { and define elements that could be replicated by employers in underserved } \\
\text { communities. } \\
\text { - Move beyond pre/post program studies to prospective controlled studies, ideally } \\
\text { with randomization. } \\
\text { - Develop a standardized set of effectiveness metrics for summertime program } \\
\text { evaluations. } \\
\text { Understand how supports for parents and caregivers can shape family-based and } \\
\text { informal experiences into opportunities for growth across the four areas of well- } \\
\text { being. } \\
\text { Conduct studies on how to implement, disseminate, and scale effective programs } \\
\text { and practices. }\end{array}$ \\
\hline $\begin{array}{l}\text { Developmental } \\
\text { trajectories }\end{array}$ & $\begin{array}{l}\text { - Conduct longitudinal studies that examine the effect of different types of } \\
\text { summertime experiences over the course of childhood/adolescence and the } \\
\text { effect on long-term developmental outcomes for children and youth. } \\
\text { - Conduct research on resilience and asset-based approaches to improving } \\
\text { developmental outcomes with special attention to underserved populations. }\end{array}$ \\
\hline $\begin{array}{l}\text { Underserved } \\
\text { populations }\end{array}$ & $\begin{array}{l}\text { - Understand how community, neighborhood, and family contexts affect outcomes } \\
\text { for children and youth during the summer. } \\
\text { - Conduct research on the characteristics of programs that have been shown to be } \\
\text { who are American Indian, Alaska Native, Native Hawaiian, Pacific Islander, } \\
\text { immigrant, migrant and refugee, homeless, system-involved, LGBTQ, and those } \\
\text { with special health care or developmental needs). } \\
\text { - Understand the needs of system-involved children and youth and } \\
\text { policies/practices that can be implemented to meet their developmental needs. }\end{array}$ \\
\hline
\end{tabular}

Note. A more expansive table of research needs specific to the four outcome domains examined by the committee is available in the committee's full report. 


\section{Conclusion}

Although there is no single strategy that will work in every community for every young person, research can shed light on promising practices that, when applied with attention to the needs of the target population, have the potential to improve outcomes regardless of background. More robust data on seasonality for the four outcomes of interest in this study, as well as further research on how summers affect the development of children and youth beyond academic learning -in their social and emotional development, physical and mental health, safety/risk taking, and pro- and anti-social behavior-would offer a chance to improve outcomes and reduce the disparities and inequities that currently exist.

\section{References}

Afterschool Alliance. (2015). Summer learning programs help kids succeed. http://www. afterschoolalliance.org/documents/AA3PM-2015/National-AA3PM-Summer-FactSheet-6.11.15.pdf

Augustine, C. H., McCombs, J. S., Pane, J. F., Schwartz, H. L., Schweig, J., McEachin, A., \& Siler-Evans, K. (2016). Learning from summer: Effects of voluntary summer learning programs on low-income urban youth. RAND. https://www.rand.org/pubs/research reports/RR1557.html

Borman, G. D., Benson, J., \& Overman, L. T. (2005). Families, schools, and summer learning. The Elementary School Journal, 106(2), 131-150. https://doi.org/10.1086/499195

Borman, G. D., \& Dowling, N. M. (2006). Longitudinal achievement effects of multiyear summer school: Evidence from the teach Baltimore randomized field trial. Educational Evaluation and Policy Analysis, 28(1), 25-48.

Concentric Research and Evaluation. (2018). Examining the long-term effects of the Horizons National student enrichment program on student academic outcomes.

http://www.horizonskids.org/CustomerContent/horizonsnewcanaan/news/PDFs/Horizons National Retrospective_Study Report Novem ber 2018.pdf

Duncan, G. J., \& Murnane, R. J. (2011). Introduction. In G. J. Duncan \& R. J. Murnane (Eds.), Whither opportunity? Rising inequality, schools, and children's life chances (pp. 3-23). Russell Sage.

Durlak, J. A., Weissberg, R. P., Dymnicki, A. B., Taylor, R. D., \& Schellinger, K. B. (2011). The impact of enhancing students' social and emotional learning: A meta-analysis of school-based universal interventions. Child Development, 82(1), 405-432.

Greenberg, M., \& Weissberg, R. (2018). Social and emotional development matters: Taking action now for future generations. The Pennsylvania State University and Robert Wood Johnson Foundation. 
Journal of Youth Development | http://jyd.pitt.edu/ | Vol. 15 Issue 3 DOI 10.5195/jyd.2020.948

Shaping Positive Summertime Experiences for Youth

https://www.rwjf.org/en/library/research/2018/12/social-and-emotional-developmentmatters.html

Halle, T., Forry, N., Hair, E., Perper, K., Wandner, L., Wessel, J., \& Vick, J. (2009). Disparities in early learning and development: Lessons from the early childhood longitudinal study-birth cohort (ECLS-B). Child Trends.

Hoynes, H., Schanzenbach, D. W., \& Almond, D. (2016). Long-run impacts of childhood access to the safety net. American Economic Review, 106(4), 903-34. https://doi.org/10.3386/w18535

Kilanowski, J. F., \& Gordon, N. H. (2015). Making a difference in migrant summer school: Testing a healthy weight intervention. Public Health Nursing, 32(5), 421-429.

https://doi.org/10.1111/phn.12175

Mahoney, J. L., Larson, R. W., Eccles, J. S., \& Lord, H. (2005). Organized activities as developmental contexts for children and adolescents. In J. L. Mahoney, R. W. Larson, \& J. S. Eccles (Eds.), Organized activities as contexts of development: Extracurricular activities, after-school and community programs (pp. 3-22). Lawrence Erlbaum.

Malin, A. J., Busgang, S. A., Cantoral, A. J., Svensson, K., Orjuela, M. A., Pantic, I., Schnaas, L., Oken, E., Baccarelli, A. A., Téllez-Rojo, M. M., Wright, R. O., \& Gennings, C. (2018). Quality of prenatal and childhood diet predicts neurodevelopmental outcomes among children in Mexico City. Nutrients, 10(8). https://doi.org/10.3390/nu10081093

McLanahan, S. \& Jacobsen, W. (2015). Diverging destinies revisited. In P. R. Amato, S. L. McHale, A. Booth, \& J. Hook (Eds.), Diverging destinies: Families in an era of increasing inequality. Springer. https://doi.org/10.1007/978-3- 319-08308-7 1

McCombs, J. S., Kirby, S. N., \& Mariano, L. T. (Eds.). (2009). Ending social promotion without leaving children behind: The case of New York City. RAND Corporation.

McCombs, J. S., Augustine, C., Unlu, F., Ziol-Guest, K., Naftel, S., Gomez, C. Marsh, T., Akinniranye, G., Todd, I. (2019). Investing in successful summer programs: A review of evidence under the Every Student Succeeds act. RAND Corporation. https://www.rand.org/pubs/research reports/RR2836.html

National Research Council and Institute of Medicine. (2002). Community programs to promote youth development. National Academies Press.

National Research Council and Institute of Medicine. (2000). From neurons to neighborhoods: The science of early childhood development. National Academies Press.

https://www.nap.edu/catalog/9824/from-neurons-to-neighborhoods-the-science-of-earlychildhood-development

Reardon, S. F., \& Portilla, X. A. (2016). Recent trends in income, racial, and ethnic school readiness gaps at kindergarten entry. Aera Open, 2(3), 1-18. https://doi.org/10.1177/2332858416657343 
Journal of Youth Development | http://jyd.pitt.edu/ | Vol. 15 Issue 3 DOI 10.5195/jyd.2020.948 Shaping Positive Summertime Experiences for Youth

Simpkins, S. D., Riggs, N. R., Ngo, B., Vest Ettekal, A., \& Okamoto, D. (2017). Designing culturally responsive organized after-school activities. Journal of Adolescent Research, 32(1), 11-36. https://doi.org/10.1177/0743558416666169 